\title{
Discharge Measurements In Low Flow Conditions With ADCP Technology - First Experiences In Nepal
}

\author{
J. Merz \\ Integration environment and enegy, Kathmandu, Nepal \\ E-mail:jmerz@integration.org
}

\begin{abstract}
Low flows prevail during about nine months of the year in Himalayan rivers as a result of the influence of the monsoon climate. They account for a large portion of the annual water balance and accurate information about these flows is therefore critical for water resources planning, development, management and hydropower design. Issues that occur with the neighbouring country India are often related to low flows and make exact information on low flows a prerequisite for successful transboundary water management.
\end{abstract}

However, reliable and long-term information on low flows are generally not available as most basins are ungauged. In addition low flow measurements are often associated with measurement errors as measurement cross-sections change during the flood season. Changes in measurement cross-sections are natural, but need frequent re-surveying of the sections in order to obtain good quality discharge measurements. This is often done on in-frequent basis and changes between big flood events are not recorded. The equipment used for discharge measurements is rarely recalibrated leading to additional errors.

Internationally, in the last two decades river and stream discharge measurements have been improved with the introduction of Acoustic Doppler Current Profiler (ADCP) technology. This new technology for hydrologic data acquirement has so far not been used extensively in the Himalayan region. First experiences with a StreamPro ADCP in Nepal as a part of a technology evaluation confirmed the commonly stated advantages of this technology compared to current-meter measurements, and showed its promising potential for various future applications including the application for accurate low flow measurements.

Keywords: Discharge measurement, ADCP, low flow

\section{INTRODUCTION}

Flow regimes of Himalayan Rivers are largely determined by the highly seasonal characteristics of precipitation (Chalise et al., 2003). They are characterized by high fluctuations between the peak flows during the monsoon season from June to
September and the low flows during the remaining months of the year from October to May. According to Myint and Hofer (1998) monthly mean flows during the monsoon season are normally 10-20 times higher than the corresponding low flows. Annual water availability in the river basins is therefore largely determined by the low flows 
during nine months of the year. The quantity and variation of low flows depends on the precipitation pattern during the dry season, melting of snow and glacial melt. The latter component provides a steady flow on which agriculture in both upper and lower basins heavily depend, especially in the pre-monsoon season, the driest time of the year. Problems of water stress are already now prevalent in the region due to increasing water demands of agriculture industry and a rapidly growing population. Reduction in fresh water availability can have serious consequences for the livelihoods of the people in the region. The melt water of the Himalayas supplies some of the largest irrigation networks of the world.

Climate change is a topic of large concern in the Himalayas. Seasonality, snow and glaciers are closely correlated to the temperature regime and are therefore expected to change under the influence of global climate change. At present, the following indications for the first impacts of climate change are widely cited:

- Glaciers are melting and there are serious concerns about the alarming rate of retreat of Himalayan glaciers. The melting of glaciers is observed in the reducing number of glaciers and in the rapid increase in number and size of glacial lakes (Mool et al., 2001)

- A study on the maximum temperature trends in Nepal has shown high rates of warming in the high elevation regions of the country whereas at lower elevations, the warming was low (Shrestha et al., 1999).

These are all evidences of the impacts of global warming in the Himalayas. Such impacts of global warming are likely to increase in the coming years affecting the flow regimes of the Nepalese rivers. While in the immediate future some augmentation in low flows can be anticipated, the long-term impacts will be the gradual decrease in the low flow and in the net availability of water during the dry periods. Furthermore, decreasing snowfall in the recent years has seasonally and seriously affected water availability and food production in parts of the Western Himalayas. Similar trends are also reported from other parts of the Hindu Kush Himalayas.

As introduced above, it is evident that accurate information on low flows is critical for water resources planning, development and management. However, as Chalise et al. (2003) point out, reliable and long-term information on low flows is generally not available as most basins are ungauged. In addition, low flow measurements are often associated with measurement errors as cross-sections change during the flood season. Changes in measurement cross-sections are natural, but need frequent re-surveying of the sections in order to obtain good quality discharge measurements. This is often not done on frequent basis and changes between big flood events are not recorded. The equipment used for discharge measurements is rarely recalibrated leading to additional errors.

Acoustic Doppler Current Profiler (ADCP) technology that has been introduced in the early 1980s may provide a solution for the improvement of hydrologic measurements including the measurement of low flows. At first, ADCPs have been used primarily for oceanographic applications e.g. current profiles in great depth. Within a short time, the technology has been consistently further developed; and first applications in surface waters emerged. Being able to provide data in lower depths and to obtain not only velocities but also river discharge data directly represents a major advancement in river hydrology (Schierhuber, 2004). ADCPs gained the reputation of being 
the "most important development in stream flow measurement in the last 10 years" (Simpson 2001 cited in Hirsch/Costa 2004) due to their clear advantages compared to conventional currentmeter methods. Today, ADCPs are used for river discharge measurement by various hydrologic surveys worldwide; and technological innovations enable manifold options of ADCP applications for measurements also in low flow and shallow river conditions. It is to be noted that ADCPs are appropriate for rivers where current meter technology is appropriate. In creeks or rivers where turbulent flows are prevalent, salt dilution (Merz and Doppmann, 2006) or the use of fluorescent dye tracers have to be considered.

\section{ADCP THEORY AND EQUIPMENT}

ADCPs can be used as an efficient tool to provide a wide range of water velocity and discharge data within one single measurement process. Only small teams of 2-3 persons are required to carry out a well-prepared measurement. The field preparation for carrying out ADCP measurements is usually not very time consuming. The hardware set-up of the ADCP takes only a few minutes and a solution for fastening and moving the ADCP has to be found according to one's purposes and the particular conditions of the measurement site. All data can be replayed and reviewed at the measurement site itself and in real-time; and through several measurements at the same conditions and at the same time, the data can be field plausibility controlled, i.e. the results from different measurements at the same conditions can be directly compared and the results herewith gain robustness. This simplifies post-field work including data-qualityassurance and detailed data evaluation. Besides discharge data at different levels, water current data (i.e. flow velocity and direction) as well as information about the measurement profile (i.e. water depth and profile length) are obtained in a single measurement.

Two basic principles of acoustic physics are needed to get a rudimentary outline of ADCP water velocity and discharge measurement theory.

At first, as commonly known, in air or water transmitted sound signals can be reflected by objects and the objects' distances can be calculated through the time elapsed between transmission of the sound pulse and the receiving of the echo. This principle is used by depth sounders.

Since ADCP measurements refer more to velocities than to distances; a second principle is needed. As already stated, the ADCP transmits acoustic signals (ultrasonic waves) into the water column, which are reflected by sediments and particles carried by the water current. Both the ADCP pulse and the backscatter are in motion, which triggers a phenomenon known as the Doppler effect/shift. The basic idea of the Doppler principle is that radial motion between the source and the reflector of a sound signal causes a frequency shift of the transmitted and afterwards reflected signal (see Figure 1). To measure water velocity and discharge data, the frequencies of the backscattered (sediment reflected) signals are compared with the frequency of the originally emitted signals to calculate the velocity of the particles, and thus, the water velocity (Simpson, 2001).

Since ADCPs are moved across the water section during the measurement process, they are not only able to measure the speed and direction of water currents at various points throughout the water column, but also the flow conditions of the entire river cross-section can be captured; and thus a "current profile" may be directly calculated by the associated software (Dalkin/ Spain, 2006). 
During the measurement process three variables are measured continuously:

- Current velocity (absolute value and direction);

- ADCP's speed-over-ground (absolute value and direction); and

- Water depth.

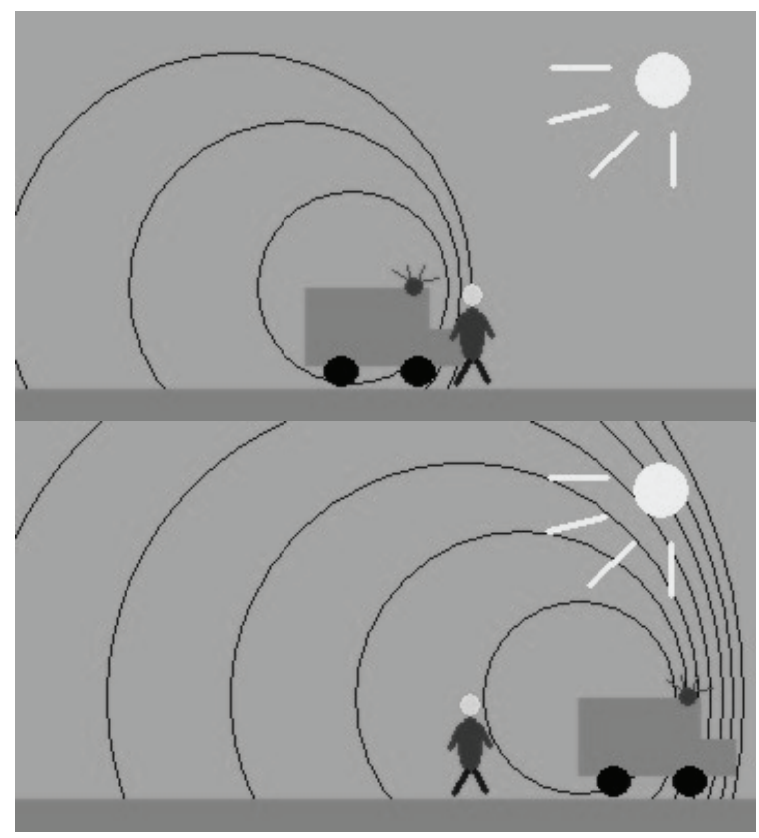

Figure 1: Doppler shift principle; left: short intervals of wave fronts with approaching vehicle, right: long intervals of wave fronts with leaving vehicle (adapted from INTEGRATION, 2008)

While conventional ADCP instruments are not able to measure in water depths lower than about $2 \mathrm{~m}$, solutions for low flow measurements for small river cross-sections and shallow streams have been developed during the past few years. The StreamPro line of RD Instruments is especially designed for acoustic water current and discharge measurements in shallow waters. By default a StreamPro ADCP can measure in streams with water velocities not faster than $2 \mathrm{~m} / \mathrm{s}$ and water depths of 15-225 cm. An upgrade extends the profiling range up to $4 \mathrm{~m}$ depth (RD Instruments, 2006).

The StreamPro ADCP can be easily transported to remote locations due to its relatively small dimensions and a weight of only $5 \mathrm{~kg}$ (including electronics, float, batteries and transducer). For the measurement it can be tethered along a rope tagline-and-pulley-system or simply on a rope from any fixed or suspended bridge.

The field measurements are managed and analysed with the software WinRiver II. The data can be observed during the measurement process as well as it can be saved and reviewed in real time. RD Instruments recommends the use of a Pocket PC jointly with the StreamPro line (RD Instruments, 2008b), and good experiences have also been made with a Bluetooth enabled notebook.

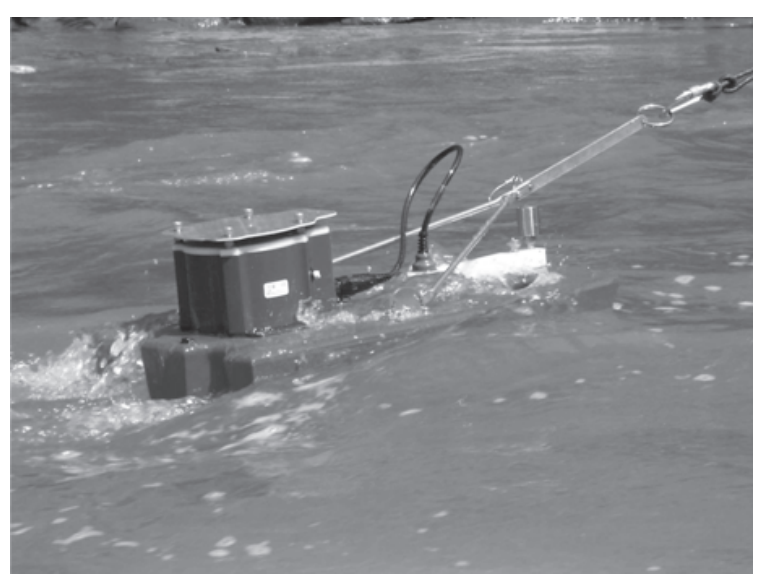

Figure 2: StreamPro ADCP in action (photo by Leonie Kappauf)

\section{COMPARISON BETWEEN ADCP AND CURRENT METER}

The main advantage of the ADCP technology in comparison to the well-established current meter method for water velocity and discharge measurements is the character of data that is 
obtained. ADCPs provide a continuous data collection throughout the water column and cross section rather than discrete point measurements. The "current profile" outputted by the ADCP associated software is closer to reality than vastly extrapolated cross-section data that can be achieved with current meters. (Lipscomb, 1996). In addition, the ADCP method does not only measure velocity but also the measurement profile. This reduces the chances of errors due to changing profiles after scouring or sedimentation at the measurement location between two measurement campaigns.

Since the time related speed-over-ground and path of travel of the ADCP are recorded, lavish taglines or other devices to hold the ADCP stationary or at a strictly straight path are obsolete (Lipscomb, 1996). In particular, there is no need to direct the ADCP perpendicular to the flow direction (Schierhuber, 2004). A well prepared data collection transect during a ADCP water current and discharge measurement should not take more than a few minutes, whereas conventional current- meter methods take multiples of this time. Moreover, despite their definitive higher time efficiency, ADCP measurements are at least as accurate as or even more accurate than current meter data.

Because of the short measurement duration, several transects can be measured in order to control the plausibility of the gathered data. In case the measurement is not providing optimal data, the measurement location can easily be shifted up- or downstream to a more appropriate location. With current meters this is often not possible, as the cable way would have to be relocated or wading is only possible at the given location. The use of the ADCP on the other hand is very flexible.

\section{FIRST EXPERIENCES AND RESULTS}

StreamPro ADCPs are especially adopted to low flow conditions and shallow waters. While carrying out a test measurement in Punyumati Khola, Panauti in September 2008, a total amount of seven transects was measured. The discharge of five of these transects varied within a range of less than five percent referring to their calculated total discharge. In order to get reciprocal pairs of transects, one transect, which could be considered to be the least accurate one, has been unchecked for the calculation of the averaged flow velocity and discharge values. The obtained summary page shows a variation between the results of the calculated total discharge of less than one percent. With a mean water velocity of approximately 0.15 $\mathrm{m} / \mathrm{s}$ and a mean water depth of $0.57 \mathrm{~m}$ over a width of $12.1 \mathrm{~m}$, the mean total discharge was $1.04 \mathrm{~m}^{3} / \mathrm{s}$ (see Table 1).

Table 1: Summary of Discharge Measurements in Punyamati Khola, September 2008

\begin{tabular}{|c|l|c|c|c|c|c|}
\hline Track & \multicolumn{1}{|c|}{ Edge } & Total Discharge [m3/s] & Area [m2] & Start time & End time & Mean Velocity [m/s] \\
\hline 003 & Left & 1.04 & 7.0 & $14: 46$ & $14: 47$ & 0.15 \\
\hline 004 & Right & 1.03 & 6.9 & $14: 47$ & $14: 49$ & 0.15 \\
\hline 005 & Left & 1.03 & 6.9 & $14: 49$ & $14: 50$ & 0.15 \\
\hline 006 & Right & 1.04 & 6.8 & $14: 51$ & $14: 53$ & 0.15 \\
\hline Mean & & 1.04 & 6.9 & & & 0.15 \\
\hline
\end{tabular}

The data collection process had been accomplished in less than half an hour. This excludes the time for field preparation e.g. set-up up of the tag-line pulley system, which required another 30 to 60 minutes 
depending on the location. However, if tethering from an existing suspension or fixed bridge is possible, field preparations are negligible. Lack of turbulence and a consistent river bed entailed very good conditions for the ADCP application. The only challenge which is implicated in measurements in such slow flow conditions is to prevent that the ADCP's speed over the ground exceeds the flow speed (Figure 3), which could possibly decline the quality of the collected data. For this reason the boat has to be pulled across the river at very low speed.

Water / Boat Speed Time Series 3 - TRDI

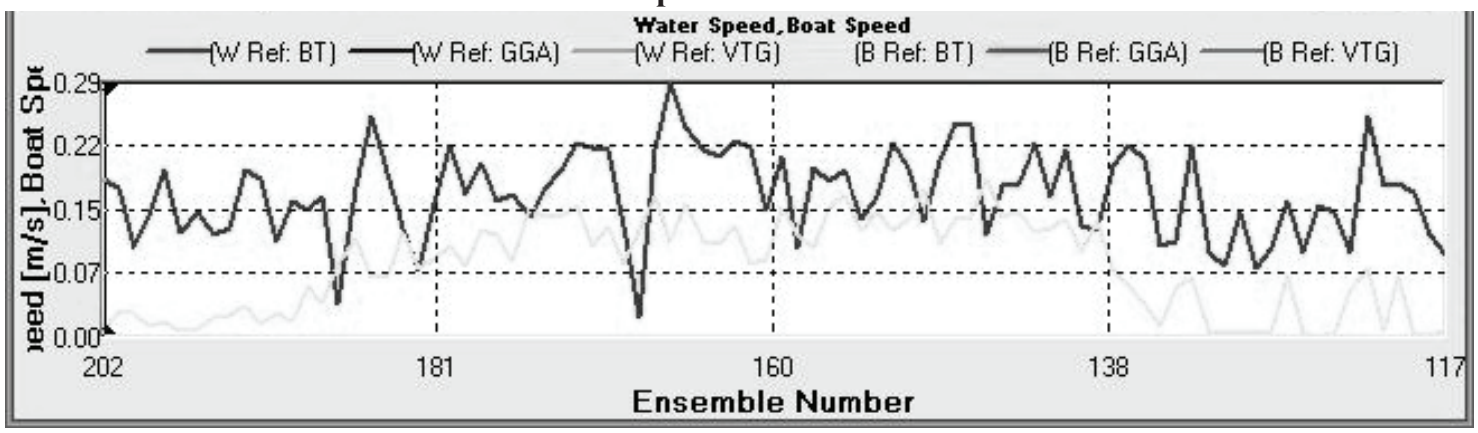

Figure 3: WinRiver II Boat /water velocity time series graph, Panauti, September 2008

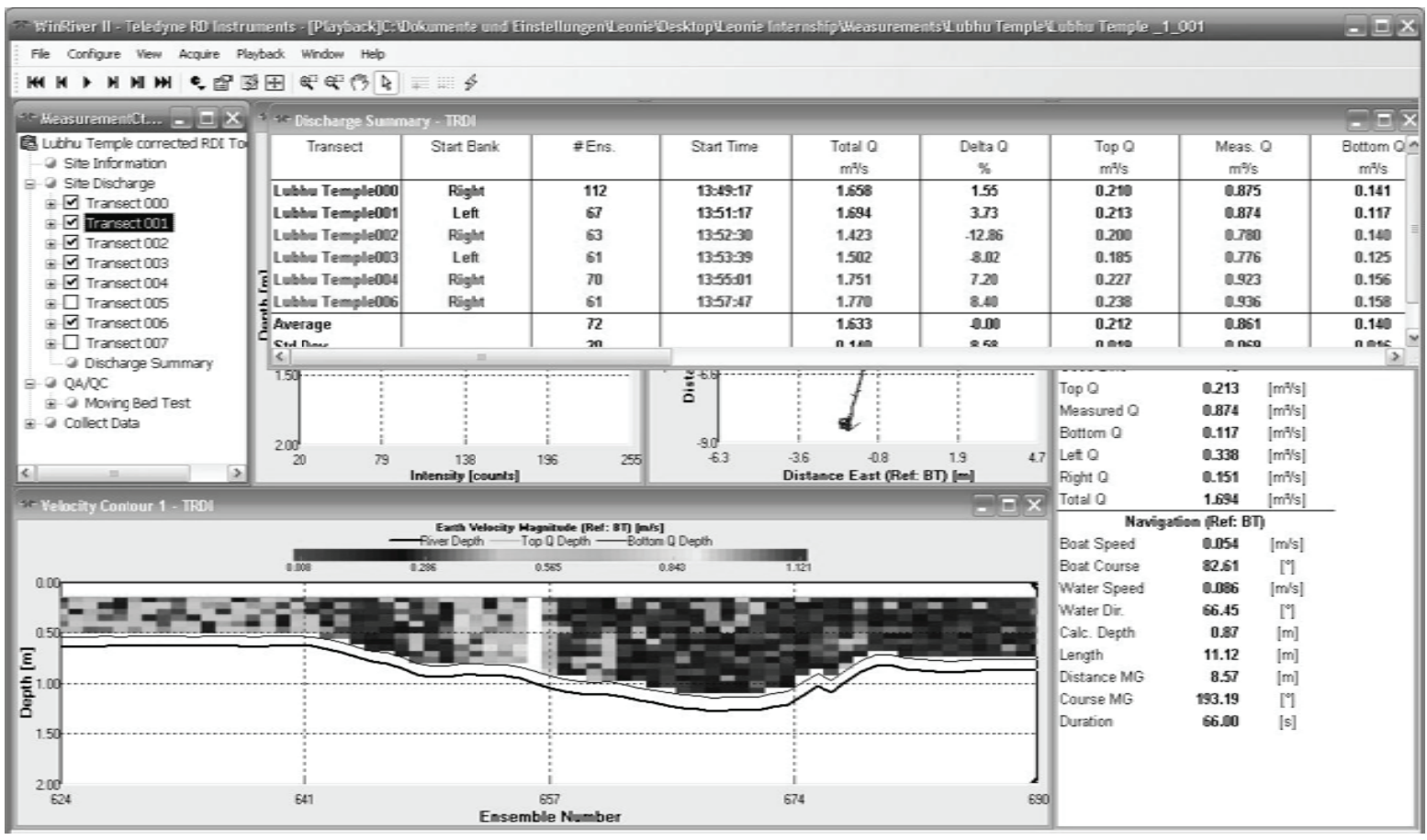

Figure 4: WinRiver II Output, Lubhu, September 2008 
Slightly more challenging conditions were encountered at Godavari Khola in Lubhu, also measured in September 2008. Despite the generally calm low flow conditions, irregularities in the riverbed caused light turbulence on the left edge which required special care during the data collection transects. Facing downstream, the left sided riverbed had fallen away more sharply (with water depth around $0.9-1.3 \mathrm{~m}$ ) than on the right bank (constantly around $0.5 \mathrm{~m}$ ).

Again seven data collection transects were implemented, this time taking only ten minutes. Because of the turbulence one or two more data collection transects would have been necessary. Nevertheless the discharge can be estimated quite precisely with the existing data and lies between $1.79 \mathrm{~m}^{3} / \mathrm{s}$ (two pairs of reciprocal transects with a variation between the single values for the total discharge of $5.82 \%$ ) and $1.72 \mathrm{~m}^{3} / \mathrm{s}$ (three transects with right and one with left start bank and $2.99 \%$ of variations between the delta $Q$ results). The width of the cross-section of this site was $12 \mathrm{~m}$, the mean water depth being around $0.96 \mathrm{~m}$. The output of this measurement from WinRiver II is shown in Figure 4.

Both examples show the massive time saving effect of ADCP measurements compared to current-meter methods. All test measurements have been carried out by small teams of two or three people. Not only data collection, but also data reprocessing and evaluation is uncomplicated and comfortable and does not require an inordinate effort in training. Once the valid data transects are selected, evaluation of data is supported by a variety of graph and tabular options which should fit most of possible needs. It is also evident that each measurement with an ADCP is plausibility controlled and better data quality can herewith be ensured.

\section{CONCLUSION}

Accurate knowledge of low flows is very important for water resources planning, development and management. However, their measurement is often associated with errors and often low flow data is missing. The application of a StreamPro ADCP may overcome some of these short comings as these measurements can be made rapidly, with better quality and cost effectively.

In general, a well prepared data collection transect during an ADCP water velocity and discharge measurement should not take more than a few minutes depending on the river conditions and the measurement location. The actual measurement follows the set-up of the tethering system which can be made much simpler than for a current meter measurement. At the same time, the accuracy of the ADCP data, however, is not compromised. Because of the possibility of several measurements at the same conditions, it is argued that the data is actually better and more reliable. Measurements are more cost effective because less staff is required and time taken for each measurement is reduced. Transport of the instrument and accessories is very easy and can be done by the measurement team themselves.

StreamPro ADCPs meet the needs of flow velocity and discharge measurements in low flow conditions. The clear advantage in time efficiency and staff requirements plays an important role in the set-up process of a more dense network of low flow hydrologic data. At the same time it is important to note that other instruments applying the same principles are also in use for sediment assessments and discharge measurements for high flows and higher flow velocities.

On the basis of these preliminary results it is recommended that 
- An intensive low flow measurement program using both ADCPs and CM procedures simultaneously is initiated;

- Based on the results from this intensive program, DHM will be able to develop a proposal for adopting the ADCP technology for low flow assessment of the rivers and streams of Nepal;

- ADCP technology is also evaluated for high flow measurements for which more expensive equipment with a higher depth range is required;

- Timely periodic re-calibration of current meters that are also used for high flows is a pre-requisite for good quality data. This is necessary even for comparison of technologies as recommended above.

\section{REFERENCES}

Blaschke, A.P.; Braunshofer, R.; Feregyhazy, H.; Gutknecht, D.; Habersack, H.; Karner, C.; Mayr, P.; Schmalfuß, R.; Schober, S.; Sengschmitt, D.; Steiner, K-H. (2002). Kolmationsprozesse am Beispiel des Stauraumes Freudenau. Projektphase II Vollstau. Schriftenreihe der Forschung im Verbund, Vol. 75. [http://www.verbund.at/ cps/rde/xbcr/SID-3E1B22D8-61AE30B8/ internet/Band_075.pdf] (25.11.2008)

Chalise, S.R.; Kansakar, S.R.; Rees, G.; Croker, K.; Zaidman, M. (2003) Management of water resources and low flow estimation for the Himalayan basins of Nepal. Journal of Hydrology 282: pp. 25-35.

Costa, J.E.; Hirsch, R.M., 2004. U.S. Stream Flow Measurement and Data Dissemination Improve. EOS Transaction American Geophysical Union, Vol. 85, No 20, 197203. [http://water.usgs.gov/osw/pubs/EOSStreamflow.pdf] (28.09.2008)
Dalkin, D.; Spain, P., 2006. ADCPs: Today's Tool for Measuring Water Currents \& Discharge, RD Instruments Application Note.

INTEGRATION environment \& energy (2008) Digital Handbook for Discharge Measurements in Surface Waters. Kathmandu: INTEGRATION environment \& energy. [CD-Rom]

Lipscomb, S. W., 1996. Quality assurance plan for discharge measurements using Broadband Acoustic Doppler Current Profilers. United States Geological Survey, Open-File Report 95-701.

Merz, J.; Doppmann, G. (2006) Measuring Mountain Stream Discharge Using the Salt Dilution Method - A practical guide. Kathmandu: International Centre for Integrated Mountain Development.

Mool, P.K.; Bajracharya, S.R.; Joshi, S.P. (2001) Inventory of Glaciers, Glacial Lakes and Glacial Lake Outburst Floods - Nepal. Kathmandu: ICIMOD

Myint A.K.; Hofer, T. (1998) Forestry and Key Asia Watersheds. International Centre for Integrated Mountain Development, Kathmandu.

RDInstruments, 2006. Frequently Asked Questions (FAQ-003), [http://www. rdinstruments.com/smartlink/sp/support docs/FAQ003\%20StreamPro\%20FAQ.pdf] (28.09.2008)

RD Instruments, 2008a WinRiver II: User's Guide, $\mathrm{P} / \mathrm{N}$ 957-6231-00

RD Instruments, 2008b. StreamPro Operation Manual, P/N 95B-6003-00

SOHAM-Nepal 
Schierhuber, A., 2004. Acoustic Doppler Current Profiler (ADCP) und dessen Einsatz in der modernen Hydrologie. Peticzka, R. (ed.). Beiträge zur Quartärforschung und Landschaftsökologie, pp. 197-206. Institut für Geographie und Regionalforschung der Universität Wien, Wien.

Simpson, M.R., 2001. Discharge Measurement Using a Broad-Band Acoustic Doppler
Current Profiler, United States Geological Survey, Open-File Report 01-1

Shrestha, A.B.; Wake, C.P.; Mayewski, P.A.; Dibb, J.E. (1999) Maximum Temperature Trends in the Himalaya and Its Vicinity: An Analysis Based on Temperature Records from Nepal for the Period 1971-94. Journal of Climate, Volume 12, Issue 9: pp. 27752786. 